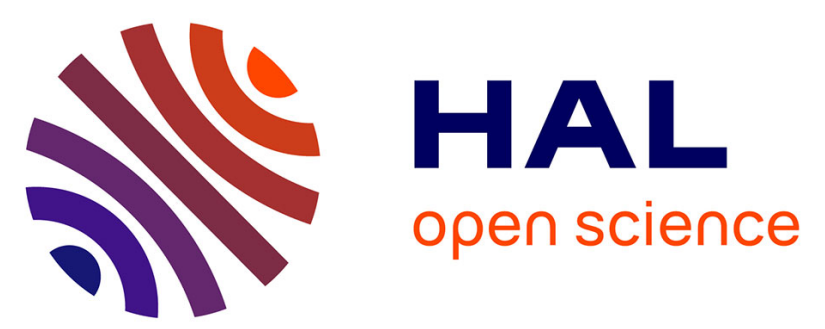

\title{
Effective population size and heterozygosity-fitness correlations in a population of the Mediterranean lagoon ecotype of long-snouted seahorse Hippocampus guttulatus
}

Florentine Riquet, Cathy Lieutard-Haag, Giulia Serluca, Lucy Woodall, Julien Claude, Patrick Louisy, Nicolas Bierne

\section{To cite this version:}

Florentine Riquet, Cathy Lieutard-Haag, Giulia Serluca, Lucy Woodall, Julien Claude, et al.. Effective population size and heterozygosity-fitness correlations in a population of the Mediterranean lagoon ecotype of long-snouted seahorse Hippocampus guttulatus. Conservation Genetics, 2019, 20 (6), pp.1281-1288. 10.1007/s10592-019-01210-3 . hal-02402560

\author{
HAL Id: hal-02402560 \\ https://hal.science/hal-02402560
}

Submitted on 10 Dec 2019

HAL is a multi-disciplinary open access archive for the deposit and dissemination of scientific research documents, whether they are published or not. The documents may come from teaching and research institutions in France or abroad, or from public or private research centers.
L'archive ouverte pluridisciplinaire HAL, est destinée au dépôt et à la diffusion de documents scientifiques de niveau recherche, publiés ou non, émanant des établissements d'enseignement et de recherche français ou étrangers, des laboratoires publics ou privés. 
1 Effective population size and heterozygosity-fitness correlations in a population

2 of the Mediterranean lagoon ecotype of long-snouted seahorse Hippocampus

3 guttulatus

4

Florentine Riquet ${ }^{1}$, Cathy Lieutard-Haag ${ }^{1}$, Giulia Serluca ${ }^{1}$, Lucy Woodall ${ }^{2,3}$, Julien Claude $^{1}$, Patrick Louisy ${ }^{4,5}$, Nicolas Bierne $^{1}$

${ }^{1}$ ISEM, Univ Montpellier, CNRS, EPHE, IRD, Montpellier, France

${ }^{2}$ Department of Zoology, University of Oxford, John Krebs Field Station, Wytham, OX2 8QJ, UK

${ }^{3}$ Natural History Museum, Cromwell Road, London SW7 5BD, UK

${ }^{4}$ ECOMERS Laboratory, University of Nice Sophia Antipolis, Faculty of Sciences, Parc Valrose, Nice, France

${ }^{5}$ Association Peau-Bleue, 46 rue des Escais, Agde, France

\section{Emails adress:}

Florentine Riquet: flo.riquet@gmail.com

Cathy Lieutard-Haag: cathy.haag@haagliautard.net

Giulia Serluca: NA

Lucy Woodall: lucy.woodall@zoo.ox.ac.uk

Julien Claude: Julien.Claude@univ-montp2.fr

Patrick Louisy: patrick.louisy@wanadoo.fr

Nicolas Bierne: nicolas.bierne@umontpellier.fr

\section{Abstract}

The management of endangered species is complicated in the marine environment owing to difficulties to directly access, track and monitor in situ. Population genetics provide a genuine alternative to estimate population size and inbreeding using nonlethal procedures. The long-snouted seahorse, Hippocampus guttulatus, is facing multiple threats such as human disturbance or by-catch, and has been listed in the red list of IUCN. One large population is found in the Thau lagoon, in the south of France. A recent study has shown this population belongs to a genetic lineage only found in Mediterranean lagoons that can be considered as an Evolutionarily Significant Unit (ESU) and should be managed with dedicated conservation strategies. In the present study, we used genetic analysis of temporal samples to estimate the effective population size of the Thau population and correlations between individual multilocus heterozygosity and fitness traits to investigate the possible expression of inbreeding depression in the wild. Non-invasive sampling of 172 seahorses for which profiles were pictured and biometric data recorded were genotyped using 291 informative SNPs. Genetic diversity remained stable over a 7year time interval. In addition, very low levels of close relatedness and inbreeding were observed, with only a single pair of related individuals in 2008 and two inbreds in 2013. We did not detect departure from identity equilibrium. The effective population size was estimated to be $\mathrm{Ne}=2742\left(\sim 40\right.$ reproductive seahorses per $\left.\mathrm{km}^{2}\right)$, larger than previously thought. No correlation was observed between heterozygosity and fluctuating asymmetry or other morphometric traits, suggesting a population with low variance in inbreeding. Together these results suggest this population does not meet conventional genetic criteria of an endangered population, as the population seems sufficiently large to avoid inbreeding and its detrimental effects. This study 
paves the way for the genetic monitoring of this recently discovered ESU of a species with patrimonial and conservation concerns.

Key words: marine endangered species, Hippocampus guttulatus, population effective size, inbreeding, heterozygosity-fitness correlations

\section{Introduction}

Marine conservation is lagging behind efforts on terrestrial ecosystems (Hendriks et al. 2006). One reason is that the marine domain is more difficult to access, making direct monitoring of populations by counting or capture-recapture more complicated to realize. DNA analysis has grown substantially over the last two decades as an alternative to determine genetic diversity and relatedness within populations, connectivity among populations, infer demographic history of populations, or even provide acute estimates of the effective population size (Caughley 1994; Frankham 1995; Luikart et al. 2010). Seahorses (Hippocampus spp.) are protected by the Convention on International Trade in Endangered Species of Wild Fauna and Flora (Appendix II; 2014) against over-exploitation through international trade, as well as by the EU Wildlife Trade Regulations (Annex B, 2014). More specifically, Hippocampus guttulatus Cuvier, 1829 is classified as DataDeficient in the International Union for Conservation of Nature Red list of threatened species, indicating the lack of knowledge of the species overall. In addition, $H$. guttulatus is listed as near threatened, vulnerable or endangered in several European countries and most European countries ratified the Berne Convention, Barcelona Convention and OSPAR Convention, all aiming to protect $H$. guttulatus. Despite legislations regarding its protected status, only a handful of studies on $H$. guttulatus have been done so far, of which a few focused on patterns of population genetics (López et al. 2015; Riquet et al. 2019; Woodall et al. 2015). Riquet et al. (2019) identified four cryptic lineages maintained by partial reproductive isolation. These lineages lie somewhere in the grey zone of speciation (Roux et al. 2016), but should be considered Evolutionarily Significant Units (ESUs) with independent conservation management plans. Within lineages, genetic homogeneity over large distances was observed (Woodall et al. 2015; Riquet et al. 2019), suggesting populations are sufficiently large and connected to maintain genetic panmixia despite sparse distribution, low mobility and the absence of dispersive stage (Foster and Vincent 2004). One of the identified lineages exclusively inhabits Mediterranean lagoons (Riquet et al. 2019). The largest population of this ESU is found in the Thau lagoon (France). Isolated in the north of the Mediterranean Sea, this population has no other evolutionary route than to adapt to global warming. It appears necessary to gather data on the vulnerability of this lagoon ecotype, before introducing any conservation management plan.

In the present study, we used three temporal samples (2006, 2008 and 2013) of Thau $H$. guttulatus to assess genetic diversity and its variability over time, as well as any demographic events. In addition, we assess inbreeding depression, by estimating inbreeding coefficients and identity disequilibrium (i.e. correlations in homozygosity), to characterize population inbreeding (David 1998; Slate et al. 2004; Balloux et al. 2004; Szulkin et al. 2010). We also tested correlations between heterozygosity and fitness traits (David 1998; Chapman 2009; Szulkin et al. 2010) using weight, lengths and fluctuating asymmetry as fitness traits. 


\section{Materials and Methods}

Sampling procedure, biometry and tissue acquisitions - Tissue samples were collected from H. guttulatus in the Thau Lagoon (France) in November 2005 and March 2006 ( $\mathrm{N}=5+8$, pooled as the 2006 sample), in December $2008(\mathrm{~N}=110)$ and in July-August 2013 (N=49). Each individual was sexed, weighed, and snout and total lengths were measured. In 2008 and 2013, right and left profiles were pictured in a standardized way using the Micro Nikkor $60 \mathrm{~mm}$ lens of a Nikon D300. Before releasing the sampled individuals, the dorsal fin was partially clipped, a non-lethal procedure (Woodall et al. 2012). Each individualized fin-clip was preserved in 96\% ethanol for subsequent genetic analyses.

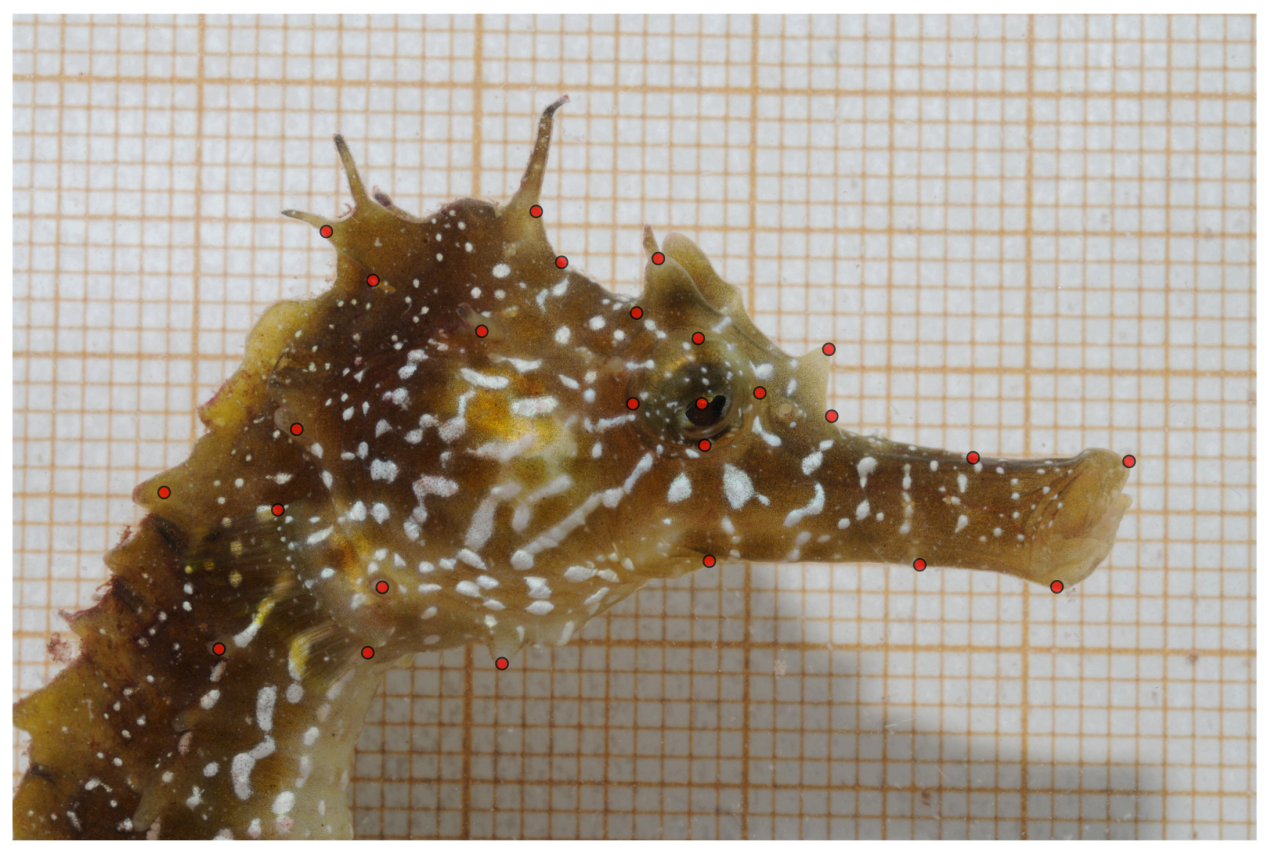

Fig. 1 Localization of the 26 landmarks used to analyze bilateral symmetry in H. guttulatus

Morphometric analyses - Shape analyses were based on geometric landmark coordinates (Claude 2008). Landmarks were chosen for an optimal coverage of the seahorse profile morphology, to compare right and left profiles, as well as their homology and repeatability among individuals. Individuals were digitized twice, on both sides, to test the significance of fluctuating asymmetry. A total of 26 landmarks were digitized on each image (Fig. 1) using tpsDig v2.17 (Rohlf 2010), then imported in R (R Development Core Team, 2011) and analyzed using Claude's R functions (Claude 2008). To screen out all non-shape difference (e.g. scale, position and orientation), we first conducted a partial Generalized Procrustes Analysis (GPA) superimposition (Rohlf and Slice 1990; Dryden and Mardia 1998). We then investigated whether fluctuating asymmetry (random deviations from perfect bilateral), directional asymmetry (significantly biased deviations from perfect bilateral towards one side) and symmetric inter-individual variation were present in our data. To estimate component of symmetric and asymmetric variation in size (Palmer 1994), we performed a mixed effect analysis of variance on centroid size with individual, side and their interaction. To test shape asymmetry, we performed a PCA on the 
coordinate matrix, then run a MANOVA (Wilks 1932) using the same factors as for the size analysis.

Because these indices were present for just one subset, we later computed index of the mean asymmetry (computed as shape difference between both sides, i.e. square root of the sum of squared procrustes differences between sides) per individual. Departure from equilibrium was tested as well as putative correlations with genetic stress such as inbreeding.

DNA extraction and Genetic Analyses - DNA was extracted using a standard cetyltrimethylammonium bromide chloroform:isoamyl alcohol (24:1) protocol (Doyle and Doyle 1987). We checked quality and quantity of DNA extraction on an agarose gel, and equalized to $35 \mathrm{ng} . \mu \mathrm{L}^{-1}$ using Qubit Fluometric Quantitation (Invitrogen). SNPs were genotyped using GoldenGate Genotyping Assay with VeraCode technology at ADNid company (Montpellier, France). Details regarding SNP calling are provided in Riquet et al. (2019). Allelic richness $\left(A_{r}\right.$, i.e. the expected number of alleles corrected for sampling size based on a rarefaction method) was estimated using the R package diveRsity (Keenan 2013). We used Genepop on the Web (Rousset 2008) to estimate allelic frequencies, expected heterozygosity $\left(\mathrm{H}_{\mathrm{e}}\right)$, fixation index $\left(\mathrm{F}_{\mathrm{IS}}\right)$ and to test both departure from Hardy-Weinberg equilibrium (10000 dememorization steps, 500 batches and 5000 iterations per batch) and temporal genetic structure.

Relatedness coefficients between all pairs of individuals were computed using the approach described in Wang (2007), implemented in COANCESTRY 1.0.0.1 (Wang 2011). This approach uses maximum likelihood (ML) to infer the relatedness coefficient between two individuals given population allele frequencies. We set error rates of $10^{-6}$ per locus. Mean relatedness coefficients and their 95\% confidence intervals were estimated with a bootstrap procedure (500 bootstraps). Simulations based on all genotypes were also run to compare calculated and expected relatedness estimates.

Individual Multi-Locus Heterozygosity (MLH) was calculated for each individual. In a population with variance in inbreeding, inbred individuals are less heterozygous (i.e. lower MLH). Inbreeding variance generates Identity Disequilibria (ID) -i.e. correlations in homozygosity across loci, a measure of departure from random associations between loci (Szulkin et al. 2010). ID were measured in 2008 and 2013 specimens by calculating the parameter $\mathrm{g}_{2}$ and its standard deviation using the software RMES (David et al. 2007), but the sample size of specimens from 2006 was too low to conduct such an analysis. The $\mathrm{g}_{2}$ parameter measures the excess of double heterozygotes at two loci relative to the expectation under a random association, standardized by average heterozygosity (Szulkin et al. 2010), providing a measure of genetic associations and inbreeding variance in the population. To test for the significance of $\mathrm{g}_{2}$, random re-assortments of single-locus heterozygosities among individuals were tested 1000 times (David et al. 2007).

Finally, we tested for heterozygosity-fitness correlations (Chapman 2009; Szulkin 2010) by looking for correlations between MLH and phenotypic data (measurements, weight and Asymmetrical Index). Spearman correlations (Spearman 1904) were computed using the software package R (R Development Core Team, 2011).

Ne Estimations - Estimating $\mathrm{N}_{\mathrm{e}}$ is challenging, and large variance in performance among methods is commonplace (Gilbert and Whitlock 2015; Riquet et al. 2016). Therefore the use of several independent methods is recommended to improve 
accuracy (Waples 2005; Fraser et al. 2007; Waples and Do 2010; Hare et al. 2011).

182 We used the two types of methods to estimate the effective population size that were 183 found to produce the best results when the study population experienced no migration 184 (Gilbert and Whitlock 2015). First, $\mathrm{N}_{\mathrm{e}}$ was estimated by measuring temporal changes 185 in allele frequencies between two diachronic samples separated by 7 and 5 years 186 (Waples 1989). The pseudo-likelihood based approach (Wang 2001), implemented in 187 MLNe 2.3 (Wang and Whitlock 2003) was used. We set maximum $\mathrm{N}_{\mathrm{e}}$ at 10 000, 188 higher than the census size $\left(\mathrm{N}_{\mathrm{c}}\right)$ estimated by Louisy and Bérenger (2015). The mean 189 age of reproducing adults in a population that contributed to a cohort was estimated to 1901.8 years, the reproductive output assumed constant through age with a life span 191 estimated to ca. 5 years (Curtis and Vincent 2006, Louisy and Bérenger 2015). With a generation time unknown, we set it to 2 years and we also tested longer generation times (3- and 5- year generation time). The effective number of breeders that produced the sample $\left(\mathrm{N}_{\mathrm{b}}\right)$ was also estimated (Waples 2005) with 2008 and 2013 samples. We measured the nonrandom association of alleles at different loci within a sample (Hill, 1981) using a bias correction (Waples 2006; Waples and Do 2008) implemented in NeEstimator v2 (Do et al. 2014). Following the recommendations of Waples and Do (2010), we excluded alleles with frequencies below 0.02 and according to $H$. guttulatus reproductive characteristics, monogamy was applied.

\section{Results}

\section{Fluctuating asymmetry in the Thau lagoon population}

Individuals with only one usable image per profile were removed from the analyses, resulting in 77 individuals from 2008 being analyzed using 26 landmarks. Significant fluctuating and directional asymmetries on the size were observed (ANOVAs $F=$ 4.62 and $F=4.41, p$-value $=0.03$ and $p$-value $=0.04$, respectively). Shape fluctuating asymmetry was still significant (MANOVA $F=3.16 p$-value $=2.210^{-16}$ ), while directional asymmetry was not (MANOVA $F=1.29, p$-value $=0.23$ ). 
A)

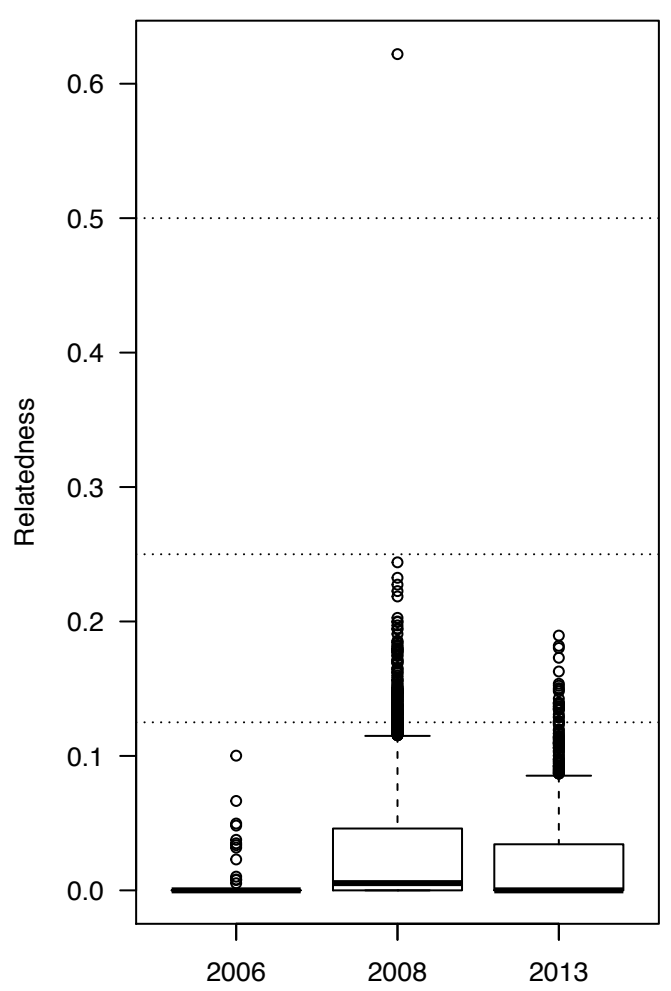

B)

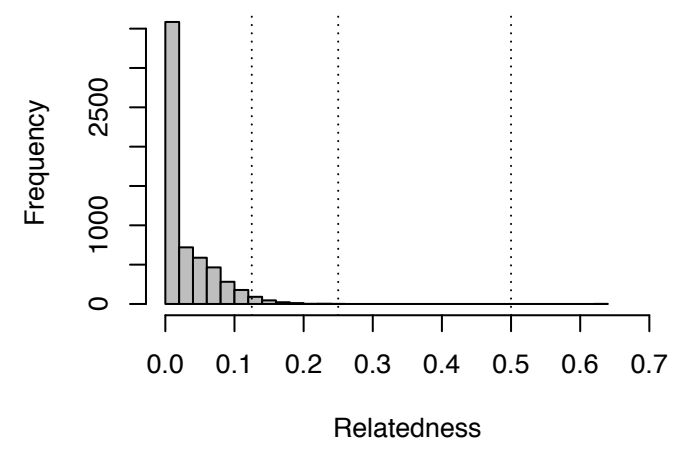

C)

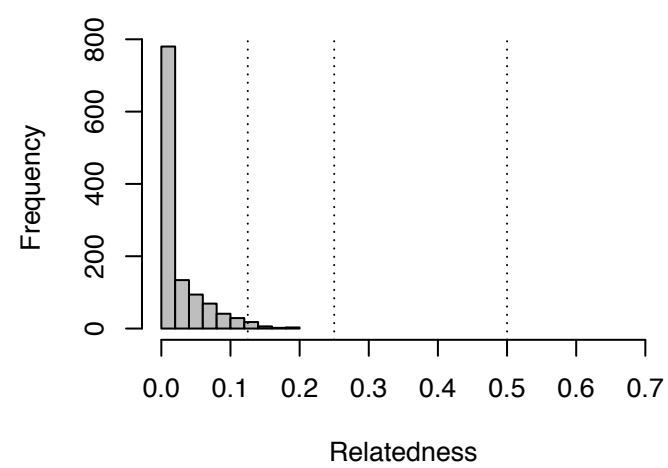

Fig. 2 Pairwise relatedness coefficient estimates among $H$. guttulatus sampled in 2006, 2008 and 2013. Dotted lines highlight a relatedness coefficient of 0.5 (e.g. full sibs or parent-offspring), 0.25 (half-sibs or grandparent-grandchild) and 0.125 (first cousins, aunt/uncle - offspring). A) Pairwise relatedness in each sample. B) Frequency of pairs of individuals distribution in 2008. C) Frequency of pairs of individuals distribution in 2013. Frequency of pairs of individuals distribution in 2006 is not shown $(\mathrm{N}=13)$.

\section{Diversity and relatedness in the Thau lagoon population}

Monomorphic loci among all individuals or loci with minor allelic frequencies lower than 5\% were removed, so that we used 291 SNPs for all 172 individuals, with no missing data. All loci showed heterozygotes in every sample (2006, 2008 and 2013) and genetic diversity remained stable over time $\left(\mathrm{A}_{\mathrm{r}-2006}=1.89, \mathrm{~A}_{\mathrm{r}-2008}=1.93\right.$ and $\mathrm{A}_{\mathrm{r}-}$ ${ }_{2013}=1.92 ; \mathrm{H}_{\mathrm{e}-2006}=0.336, \mathrm{H}_{\mathrm{e}-2008}=0.328$ and $\mathrm{H}_{\mathrm{e}-2013}=0.326 ; p$-values $\left.>0.99\right)$. Note that 13 samples were used to estimate $\mathrm{A}_{\mathrm{r}}$, i.e. a measure of genetic diversity that takes into account variation of sample size. No departure from Hardy-Weinberg equilibrium was observed $\left(\mathrm{F}_{\text {IS-2006 }}=0.0001, \mathrm{~F}_{\text {IS-2008 }}=0.006, \mathrm{~F}_{\text {IS-2013 }}=0.008 ; p\right.$-values $\left.>0.99\right)$ along with no temporal genetic differentiation $\left(\mathrm{F}_{\mathrm{ST}}=0.0001, p\right.$-value $\left.=0.91\right)$. We estimated relatedness using the assumptions of inbreeding and no inbreeding (Wang 2007) and similar results were obtained. As there was little evidence for inbreeding (see below), we present results with no inbreeding. Relatedness coefficients ranged from 0 to 0.10 in 2006 (mean $\pm \mathrm{sd}=0.006 \pm 0.017$ ), from 0 to 0.62 in 2008 (mean $\pm \mathrm{sd}=0.027 \pm 0.038$ ) and from 0 to 0.19 in 2013 (mean $\pm \mathrm{sd}=$ $0.022 \pm 0.034$; Fig. 2). Relatedness was not significantly different between the three 
study years $(p$-value $=0.93)$. Based on simulations, relatedness estimator comparisons between the calculated relatedness coefficient values and the expected relatedness values were not significantly different (expected levels of relatedness $r=0.005,0.26$ and 0.21 in 2006, 2008 and 2013, respectively; Wilcoxon signed ranks test, $Z=-$ $1.807, p$-value $=0.071)$. Over all dyad comparisons, only one $(0.01 \%)$ was identified with a relatedness coefficient higher than 0.5 , suggesting the presence of parentoffspring or full sibling pairs in 2008 (Fig. 2B). In 2008, most relatedness estimates $(97.54 \%)$ of relatedness coefficients values were lower than 0.125 (i.e. first cousins relatedness) while $2.45 \%$ ranged from 0.125 to 0.25 (i.e. halfsibs, avuncular, grandparent-grandchild relatedness), suggesting that most dyads remained mostly unrelated. In 2013, a similar pattern was seen with a maximum relatedness estimate of $0.189 ; 97.8 \%$ of relatedness coefficients estimates were lower than 0.125 while $2.28 \%$ ranged from 0.125 to 0.25 . While in 2006, all relatedness estimates were lower than 0.125 .
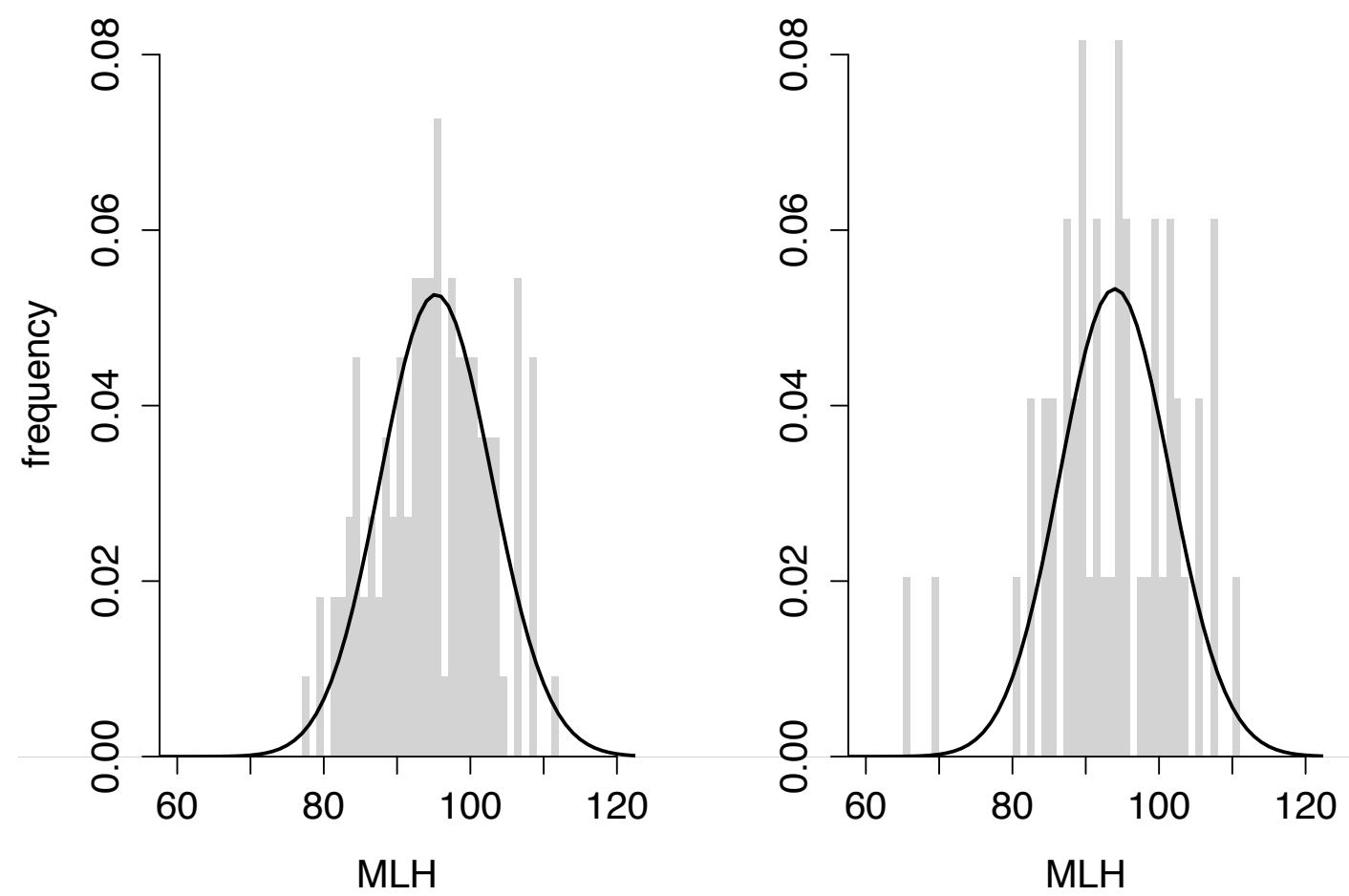

Fig. 3 Distributions of observed multi-locus heterozygosity (in gray) and expected multi-locus heterozygosity under random mating (black lines) in 2008 (A) and 2013 (B).

\section{Heterozygosity-Fitness correlations}

Multi - Locus Heterozygosity (MLH) ranged from 85 to 111 in 2006 (mean $\pm \mathrm{sd}=98$ \pm 8.0 ), from 77 to 111 in 2008 (mean $\pm \mathrm{sd}=94 \pm 7.7$ ) and from 65 to 110 in 2013 (mean $\pm \mathrm{sd}=93 \pm 9.3$; Fig. 3, data of 2006 not shown). MLHs were normally distributed (Shapiro test $p$-values $=0.24,0.61$ and 0.16 in 2006, 2008 and 2013, 
respectively; Fig. 3, data of 2006 not shown) and no difference in MLH distribution

265 was observed over time (t-test $p$-value $=0.38$ ). Identity disequilibrium, i.e. a measure of departure from random associations of homozygosity between loci, was only identified in $2013\left(\mathrm{~g}_{2}=0.003, p\right.$-value $\left.=0.015\right)$, mainly due to two individuals with low MLH (Fig. 3). This suggests that these individuals may be inbred. No identity disequilibrium remained when removing these two individuals $\left(\mathrm{g}_{2}=0.00002, p\right.$-value $\left.=0.46\right)$. No identity disequilibrium was identified in $2008\left(\mathrm{~g}_{2}=0.0002, p\right.$-value $\left.=0.42\right)$.

Heterozygosity did not correlate with fitness traits, regardless of trait tested (Asymmetry Index estimated in 2008 per individual with its replicate, snout length,

\section{Discussion}

Indirect study using predictions of population genetics produces particularly valuable information for marine species (Waples 1998). In the present study, genetic diversity of the isolated Thau population of the Mediterranean lagoon ecotype of $H$. guttulatus proved to remain stable over a seven-year period. We did not identify significant temporal genetic structure, departure from Hardy-Weinberg nor identity equilibrium. Most individuals were likely unrelated and the population mainly outbred, with a unique pair of related individuals identified in 2008, and two inbred individuals in 2013. Heterozygosity did not significantly correlate with fitness traits, reflecting a population with no strong variance in inbreeding, and therefore no evidence of inbreeding depression (Szulkin et al. 2010). All results suggest that the Thau lagoon $H$. guttulatus population is large and panmictic and therefore will not be affected by the detrimental effects of genetic drift and inbreeding.

We observed only two inbred individuals in our sample of 172 seahorses. $H$. guttulatus is usually described sedentary, with low mobility, although it may disperse up to $150 \mathrm{~m}$ in a single day (Caldwell and Vincent 2012) with home ranges of up to $400 \mathrm{~m}^{2}$ (Garrick-Maidment et al. 2010). However they are thought to undergo seasonal migrations and have an ontogenic habitat shift. Regarding the inbred crosses found in this study, relatives may have mated because dispersal is not effective or because they dispersed collectively (Broquet et al. 2013; Yearsley et al. 2013). Inbreeding variance was not observed in our samples using identity disequilibrium $\left(\mathrm{g}_{2}\right)$ and Heterozygosity-Fitness Correlations (HFCs) were not identified. HFCs have been widely examined in natural populations (review in Chapman et al. 2009), although such correlations should only be detected in population with a high variance of inbreeding (Bierne et al. 2000; Szulkin et al. 2010). Our results suggest the study population of seahorse does not seem suffering from inbreeding depression, even if inbreeding could occur in the Thau lagoon. 
The census size of the Thau population of $H$. guttulatus is thought to have varied by factors from 1 to 10 over time according to an 8-year SCUBA-diving survey (Louisy and Bérenger 2015). Although protocols were modified throughout the survey, making dives difficult to compare, this monitoring gave an overview of Thau H. guttulatus fluctuations, with a minimum size observed in 2006 following lagoon pollution events, and a maximum in 2009-2010 (Louisy and Bérenger 2015). As expected the effective population size $\left(\mathrm{N}_{\mathrm{e}}\right)$ remained stable from 2006 to 2013 and reflects the harmonic mean of the census size over that period. Indeed, not all adults effectively reproduce; hence, $\mathrm{N}_{\mathrm{e}}$ estimates correspond to the smallest census size of the study time series. Our estimate therefore corresponds to oscillation minima of the population size. Therefore the population of $H$. guttulatus in this $75 \mathrm{~km}^{2}$ lagoon $(\sim 50$ individuals $\mathrm{km}^{-2}$ ) is likely large enough that demographic events would not impact genetic diversity much, a result in agreement with large scale genetic studies (López et al. 2015; Woodall et al. 2015; Riquet et al. 2019). Such fluctuations in census size population were also observed in the Ria Formosa coastal lagoon (southern Portugal). H. guttulatus declined by $94 \%$ over 5 years (Curtis and Vincent 2006; Caldwell and Vincent 2012) due to a combination of habitat loss (Curtis 2007; Gamito 2008; Correia et al. 2015) and coastal ocean warming (Teles-Machado et al. 2007), and is now recovering (Correia et al. 2015). In Galicia, similar effective population size estimates have been obtained (López et al. 2015). Although $\mathrm{N}_{\mathrm{e}}$ estimates should be considered with caution (Hare et al. 2011), H. guttulatus $\mathrm{N}_{\mathrm{e}}$ estimates are larger than most endangered species (e.g. Chapman et al. 2002; Hoarau et al. 2005), which should ensure the maintenance of genetic variation across the longer term providing appropriate management practices are maintained.

Seahorses are characterized by a strong parental investment, ensuring reproductive success even at low densities. This was hypothesized to make them more able to endure severe population demographic events such as bottleneck events caused by environmental perturbations for instance, when compared to species with low parental investment (Romiguier et al. 2014). Traill et al. (2010) showed that exceeding the number of individuals required for management and conservation plans will ensure the viability and longevity of the population. In this context, monitoring the Thau population of $H$. guttulatus over time is important in order to foster the results observed here, especially facing the global warming and other threats they will have to face.

Genetic monitoring of this recently discovered conservation unit in $H$. guttulatus should continue to quantify any temporal changes in population genetic metrics in response to ever-increasing anthropogenic changes to natural ecosystems, which may affect the long-term status of this lineage. Keeping H. guttulatus an ambassador in marine conservation makes sense. Facing alarming statistics regarding marine biodiversity decline and efforts (Hendriks et al. 2006; Lotze et al. 2006), fascinating and iconic marine species, such as $H$. guttulatus, act efficiently as flagship for other endangered species and ecosystems such as Mediterranean lagoons (PérezRufaza et al. 2011).

\section{Acknowledgment}

We are very grateful to local citizens, especially fishermen and divers, for their great help in collecting the fin samples used in this work. This work was funded by Languedoc-Roussillon Region "Chercheur(se)s d'avenir" (Connect7 project), by a LabEx CeMEB postdoctoral fellowship to FR, by Chocolaterie Guylian and a Natural 
Environment Research Council Industrial Case studentship (NER/S/C/2005/13461) to PL. This is article 2019-XXX of Institut des Sciences de l'Evolution de Montpellier.

\section{References}

Balloux F, Amos W, Coulson T. 2004. Does heterozygosity estimate inbreeding in real populations? Molecular Ecology 13:3021-3031.

Bierne N, Tsitrone A, David P. 2000. An inbreeding model of associative overdominance during a population bottleneck. Genetics 155:1981-1990.

Broquet T, Viard F, Yearsley JM. 2013. Genetic drift and collective dispersal can result in chaotic genetic patchiness. Evolution 67:1660-1675.

Caldwell IR, Vincent ACJ. 2012. A sedentary fish on the move: effects of displacement on long-snouted seahorse (Hippocampus guttulatus Cuvier) movement and habitat use. Environmental Biology of Fishes 96:67-75.

Caughley G. 1994. Directions in conservation biology. Journal of animal ecology 63:215-244.

Chapman RW, Ball AO, Mash LR. 2002. Spatial homogeneity and temporal heterogeneity of red drum (Sciaenops ocellatus) microsatellites: effective population sizes and management implications. Marine Biotechnology 4:589603.

Chapman, J. R., S. Nakagawa, D. W. Coltman, J. Slate, and B. C. Sheldon. 2009. A quantitative review of heterozygosity-fitness correlations in animal populations. Molecular Ecology 18:2746-2765.

Claude J. 2008. Morphometrics with R. Springer, New York

Correia M, Caldwell IR, Koldewey HJ, Andrade JP, Palma J. 2015. Seahorse (Hippocampinae) population fluctuations in the Ria Formosa Lagoon, south Portugal. Journal of Fish Biology 87:679-690.

Curtis JMR. 2007. Validation of a method for estimating realized annual fecundity in a multiple spawner, the long-snouted seahorse (Hippocampus guttulatus), using underwater visual census. Fishery Bulletin 105:327-337.

Curtis JMR, Vincent ACJ. 2006. Life history of an unusual marine fish: survival, growth and movement patterns of Hippocampus guttulatus Cuvier 1829. Journal of Fish Biology 68:707-733.

David P. 1998. Heterozygosity-fitness correlations: new perspectives on old problems. Heredity 80:531-537.

David P, Pujol B, Viard F, Castella V, Goudet J. 2007. Reliable selfing rate estimates from imperfect population genetic data. Molecular Ecology 16:2474-2487.

Do C, Waples RS, Peel D, Macbeth GM, Tillett BJ, Ovenden JR. 2014. NeEstimator v2: re-implementation of software for the estimation of contemporary effective population size ( $\mathrm{Ne}$ ) from genetic data. Molecular Ecology Resources 14:209-214.

Doyle J, Doyle J. 1987. A rapid DNA isolation procedure for small quantities of fresh leaf tissue. Phytochemical Bulletin 19:11-15.

Dryden IL, Mardia KV. (1998). Statistical shape analysis. John Wiley \& Sons, Ltd, Chichester. p XIX, 5

Foster SJ, Vincent ACJ. 2004. Life history and ecology of seahorses: implications for conservation and management. Journal of Fish Biology 65:1-61.

Fraser DJ, Hansen MM, Østergaard S, Tessier N, Legault M, Bernatchez L. 2007. Comparative estimation of effective population sizes and temporal gene flow in two contrasting population systems. Molecular Ecology 16:3866-3889. 

management: Revised recommendations for the 50/500 rules, Red List criteria and population viability analyses. Biological Conservation 170:56-63.

Gamito S. 2008. Three main stressors acting on the Ria Formosa lagoonal system (Southern Portugal): Physical stress, organic matter pollution and the landocean gradient. Estuarine, Coastal and Shelf Science 77:710-720.

Garrick-Maidment N, Trewhella S, Hatcher J, Collins KJ, Mallinson JJ. 2010. Seahorse tagging project, Studland Bay, Dorset, UK. Marine Biodiversity Records 3:e73 (4 pages).

Gilbert KJ, Whitlock MC. 2015. Evaluating methods for estimating local effective population size with and without migration. Evolution 69:2154-66.

Hare MP, Nunney L, Schwartz MK, Ruzzante DE, Burford M, Waples RS, Ruegg K, Palstra F. 2011. Understanding and estimating effective population size for practical application in marine species management. Conservation Biology: The Journal of the Society for Conservation Biology 25:438-449.

Hendriks IE, Duarte CM, Heip CHR. 2006. Biodiversity Research Still Grounded. Science 312:1715-1715.

Hill WG. 1981. Estimation of effective population size from data on linkage disequilibrium1. Genetic Ressources 38:209-216.

Hoarau G, Boon E, Jongma DN, Ferber S, Palsson J, Veer HWV der, Rijnsdorp AD, Stam WT, Olsen JL. 2005. Low effective population size and evidence for inbreeding in an overexploited flatfish, plaice (Pleuronectes platess $a$ L.). Proceedings of the Royal Society of London B: Biological Sciences 272:497503.

Keenan K, McGinnity P, Cross TF, Crozier WW, Prodöhl PA. 2013. diveRsity: An R package for the estimation and exploration of population genetics parameters and their associated errors. Methods Ecology Evolution 4:782-788.

López A, Vera M, Planas M, Bouza C. 2015. Conservation genetics of threatened Hippocampus guttulatus in vulnerable habitats in NW Spain: temporal and spatial stability of wild populations with flexible polygamous mating system in captivity. PLoS ONE 10:e0117538.

Lotze HK, Lenihan HS, Bourque BJ, Bradbury RH, Cooke RG, Kay MC, Kidwell SM, Kirby MX, Peterson CH, Jackson JBC. 2006. Depletion, degradation, and recovery potential of estuaries and coastal seas. Science 312:1806-1809.

Louisy P. and Bérenger L. (2015). Hippocampes et syngnathes du Golfe du Lion : état des connaissances. Association Peau-Bleue - Agence des aires marines protégées, $94 \mathrm{p}$.

Luikart G, Ryman N, Tallmon DA, Schwartz MK, Allendorf FW. 2010. Estimation of census and effective population sizes: the increasing usefulness of DNA-based approaches. Conservation Genetics 11:355-373.

Palmer AR. 1994. Fluctuating asymmetry analyses: a primer. Pp. 335-364 in T. A. Markow, ed. Developmental Instability: its Origins and Evolutionary Implications: Proceedings of the International Conference on Developmental Instability: Its Origins and Evolutionary Implications, Tempe, Arizona, 14-15 June 1993. Springer Netherlands, Dordrecht.

Pérez-Ruzafa A, Marcos C, Pérez-Ruzafa IM. 2011. Mediterranean coastal lagoons in an ecosystem and aquatic resources management context. Physics Chemistry Earth Parts ABC 36:160-166. 
R Core Team (2017). R: A language and environment for statistical computing. $\mathrm{R}$ Foundation for Statistical Computing, Vienna, Austria. URL https://www.Rproject.org/.

Riquet F, Le Cam S, Fonteneau E, Viard F. 2016. Moderate genetic drift is driven by extreme recruitment events in the invasive mollusk Crepidula fornicata. Heredity 117:42-50.

Riquet F, Liautard-Haag C, Woodall L, Bouza C, Louisy P, Hamer B, Otero-Ferrer F, Aublanc P, Béduneau V, Briard O, El Ayari T, Hochscheid S, Belkhir K, Arnaud-Haond S, Gagnaire P-A, Bierne N. 2019. Parallel pattern of differentiation at a genomic island shared between clinal and mosaic hybrid zones in a complex of cryptic seahorse lineages. Evolution 73:817-835.

Rohlf FJ. (2010). tpsDig. Stony Brook, NY: Department of Ecology and Evolution, State University of New York.

Rohlf FJ, Slice D. 1990. Extensions of the procrustes method for the optimal superimposition of landmarks. Systematic Biology 39:40-59.

Romiguier J et al. 2014. Comparative population genomics in animals uncovers the determinants of genetic diversity. Nature 515:261-263.

Rousset F. 2008. genepop'007: a complete re-implementation of the genepop software for Windows and Linux. Molecular Ecology Resources 8:103-106.

Roux C, Fraïsse C, Romiguier J, Anciaux Y, Galtier N, Bierne N. 2016. Shedding light on the grey zone of speciation along a continuum of genomic divergence. PLOS Biology 14:e2000234.

Slate J, David P, Dodds KG, Veenvliet BA, Glass BC, Broad TE, McEwan JC. 2004. Understanding the relationship between the inbreeding coefficient and multilocus heterozygosity: theoretical expectations and empirical data. Heredity 93:255-265.

Spearman C. 1904. "General intelligence," objectively determined and measured. American Journal of Psychology, 15: 201-292.

Szulkin M, Bierne N, David P. 2010. Heterozygosity-Fitness Correlations: A time for reappraisal. Evolution 64:1202-1217.

Teles-Machado A, Peliz Á, Dubert J, Sánchez RF. 2007. On the onset of the Gulf of Cadiz Coastal countercurrent. Geophysical Research Letters 34:L12601.

Traill LW, Brook BW, Frankham RR, Bradshaw CJA. 2010. Pragmatic population viability targets in a rapidly changing world. Biological Conservation 143:2834.

Wang J. 2001. A pseudo-likelihood method for estimating effective population size from temporally spaced samples. Genetic Ressources 78:243-257.

Wang J. 2007. Triadic IBD coefficients and applications to estimating pairwise relatedness. Genetics Research 89:135-153.

Wang J, Whitlock MC. 2003. Estimating effective population size and migration rates from genetic samples over space and time. Genetics 163:429-446.

Waples RS. 1989. A generalized approach for estimating effective population size from temporal changes in allele frequency. Genetics 121:379-391.

Waples RS (1998) Separating the wheat from the chaff: Patterns of genetic differentiation in high gene flow species. Journal of Heredity. 89: 438-450.

Waples RS. 2005. Genetic estimates of contemporary effective population size: to what time periods do the estimates apply? Molecular Ecology 14:3335-3352.

Waples RS. 2006. Seed banks, salmon, and sleeping genes: effective population size in semelparous, age-structured species with fluctuating abundance. The American Naturalist 167:118-135. 
Waples RS, Do C. 2008. ldne: a program for estimating effective population size from data on linkage disequilibrium. Molecular Ecology Resources 8:753-756.

Waples RS, Do C. 2010. Linkage disequilibrium estimates of contemporary Ne using highly variable genetic markers: a largely untapped resource for applied conservation and evolution. Evolutionary Applications 3:244-262.

\section{Wilks SS. 1932. Certain generalizations in the analysis of variance, Biometrika, 24:}

519 471-494.

520 Woodall LC, Jones R, Zimmerman B, Guillaume S, Stubbington T, Shaw P, Koldewey HJ. 2012. Partial fin-clipping as an effective tool for tissue sampling seahorses, Hippocampus spp. Journal of the Marine Biological Association of the United Kingdom 92:1427-1432. population structure in a small coastal fish, the European long snouted seahorse Hippocampus guttulatus. Conservation Genetics:1-15.

Yearsley JM, Viard F, Broquet T. 2013. The effect of collective dispersal on the genetic structure of a subdivided population. Evolution 67:1649-1659. 